\title{
Ensaio sobre a Percepção
}

\author{
Cláudia Maria Moura Pierre ${ }^{l}$
}

Resumo: Há, basicamente, duas concepções acerca de como percebemos o mundo. O primeiro é aquele em que outorgamos autonomia ao observado. O observado é considerado independente do observador, sendo este um mero agente passivo das informações dadas por ele. A segunda concepção é a que expressa a nova epistemologia científica. Para a Biologia da Cognição, o fenômeno perceptivo está incorporado à nossa experiência. Toda experiência cognitiva envolve ao que se conhece de uma maneira pessoal, enraizada na própria estrutura biológica de quem conhece. O modo como percebemos o mundo tem a ver com a forma como estamos feitos, com nossa estrutura, com nossa própria capacidade perceptiva.

Palavras Chaves: Percepção; Cognição; Experiência cognitiva.

\section{Essay on Perception}

\begin{abstract}
There are basically two views on how we perceive the world. The first is one in which we grant autonomy to the observed. The observed is considered to be independent of the observer, which is a mere passive agent of the information observed by him. The second idea is what is expressed in the new scientific epistemology. For the Biology of Cognition, the perceptual phenomenon is implicated in our experience. All cognitive experience involves what is known in a personal way, rooted in the very biological structure of who knows. The way we perceive the world has to do with how we are: with our structure and with our own perceptive ability.
\end{abstract}

Keyworlds: Perception, Cognition, cognitive Experience

O processo perceptivo está fundado na concepção da separação entre o sujeito cognoscente e aquilo que é cognoscível. Nosso modo de ser e estar no mundo envolve essa sensação de dicotomia entre sujeito e objeto, ou usando outra terminologia, entre observador e observado.

Há, basicamente, dois modelos que indicam como percebemos o mundo. São concepções diferentes sobre a maneira de percebermos. O primeiro modelo é aquele em que outorgamos autonomia ao objeto. O objeto é considerado completamente independente do observador, sendo este um mero agente passivo das informações dadas por ele (objeto).

\footnotetext{
${ }^{1}$ Cientista Social com Mestrado em Sociologia. Doutoranda em Educação pela Universidade Federal do Ceará. Autora do livro "Culpa, Cura e Relacionamento", e de outras publicações nas áreas da Educação , Espiritualidade e Cultura de Paz..
} 
Neste modelo, 'privilegiamos' o objeto. Nesta maneira de conceber o processo perceptivo, consideramos que os objetos têm preponderância sobre o sujeito - que somos nós - e acreditamos que apenas captamos as informações vindas de fora. Daí o termo objetivo, porque faz referência a um mundo de objetos. Acreditamos que o mundo é objetivo - é o objeto que nos diz o que percebemos. E assim, somos seres passivos desse mundo que incide sobre nós. Somos meros espectadores e ficamos à mercê da exterioridade. Resta ao observador apenas registrar as informações.

Desta forma, lousa, cadeiras, mesas e pessoas dizem de si para nós, são elas que nos passam a informação do que são, seu significado, suas cores... Nos movemos como se houvesse um mundo 'lá fora' que nos indica o que ele é. Um objeto de cor vermelha, por exemplo, nos informaria a existência de um comprimento de onda da cor vermelha, é o comprimento de luz que nos diz qual sua coloração - algo portanto independente do observador e imanente ao observado.

O fato de todos verem vermelho como vermelho, nos dá a sensação de segurança e nos afirma que é assim que as coisas se processam. Seríamos apenas captadores de uma cor que existe 'fora de nós'.

Foi sob esta premissa que se formulou a teoria sobre o que é a realidade. A pressuposição de uma realidade externa e objetiva, nos colocaria como coletores de informações, de maneira tal que conseguiríamos captar um recorte deste real de maneira neutra. $\mathrm{O}$ investigador faz um mero registro de dados dos acontecimentos sem distorcer as informações de acordo com seus gostos e valores. Assim surge a idéia de neutralidade científica, que proporcionaria a legitimidade das investigações realizadas.

O mundo da solidez perceptual se desmorona ao chegarmos a uma nova compreensão de como percebemos. Para a nova epistemologia das ciências, tanto tendo como base a Física Quântica, como a Biologia da Cognição, o fenômeno perceptivo está incorporado à nossa experiência. E, toda experiência cognitiva envolve ao que se conhece de uma maneira pessoal, enraizada na própria estrutura biológica de quem conhece.

Algumas experiências foram feitas para se chegar a essa nova concepção que indica o modo como percebemos e que o processo cognitivo é dependente da organização biológica (e, acrescentamos, psicológica) dos seres vivos. No segundo modelo, é o sujeito que especifica o que é observado.

Id en line Revista de Psicologia. Ano 7, No. 21, Novembroo/2013 - ISSN 1981-1179. Edição eletrônica em http://idonline.emnuvens.com.br/id 


\section{Sombra de Cores}

Foi repetida uma experiência com sombra de cores por Humberto Maturana, doutor em Biologia pela Universidade de Harvard: dois focos de luz foram projetados, de modo cruzado, numa parede, um deles com luz branca em um holofote e uma luz branca com celofane vermelho em outro holofote. A cor de sombra resultante desse jogo de luz é azul-esverdeada. Não há comprimento de onda dessa cor, senão apenas uma distribuição própria da luz branca e da luz vermelha. O que se esperaria portanto, seriam sombras avermelhadas ou rosadas (a mistura do branco com vermelho). $\mathrm{O}$ resultado deste experimento surpreende. De onde vem o azul-esverdeado? Nas palavras de Maturana: 'estamos acostumados a pensar que a cor é uma qualidade dos objetos e da luz que deles reflete. Assim, se vejo verde deve ser porque uma luz verde chega até meus olhos, ou seja, uma luz com certo comprimento de onda. (MATURANA e VARELA, 2001, p.25).

Mas, ao se usar um aparelho para medir os comprimentos de onda desta cor, não há nenhum predomínio de comprimento de onda da cor verde. Esta experiência vem comprovar que a cor que vemos não diz respeito aos objetos 'fora de nós', então,

O essencial é que, para entender o fenômeno devemos deixar de pensar que a cor dos objetos que vemos é determinada pelas características da luz que nos chega a partir deles. Em vez disso, precisamos nos concentrar em compreender como a experiência de uma cor corresponde a uma configuração específica de estados de atividade do sistema nervoso, determinados por sua estrutura. (idem, p.27)

Diante disso, Maturana afirma que nossa experiência de um mundo colorido é, literalmente, independente da composição em longitude de onda da luz proveniente das cenas que olhamos. Isso significa que as cores não são propriedades das coisas em si; vemos as cores porque estamos constituídos de forma que a perturbação do meio resulta numa resposta em nossa retina tal que podemos ver um mundo colorido.

Portanto, o modo como percebemos o mundo tem a ver com a forma como estamos feitos, com nossa estrutura, com nossa própria capacidade perceptiva. Percebemos com nossos órgãos perceptivos; é nossa capacidade perceptiva que vai configurar o que é percebido. Outro exemplo que vem a auxiliar o entendimento é a existência dos daltônicos. Por terem uma estrutura diferente de percepção, vêem de acordo com sua própria estrutura. 
Acredito que o que é valido para essas percepções visuais é também válido para todas as outras modalidades perceptuais. Então, agimos de acordo com o que percebemos e percebemos de acordo com nossa estrutura organizacional.

Na nova epistemologia se considera as capacidades cognitivas do sujeito cognoscente. Este é o modelo científico atual, apesar de ser de difícil compreensão, não ao nível do entendimento intelectual, mas de uma introjeção dessa nova maneira de perceber como percebemos e traduzi-la em nossa conduta cotidiana. O que geralmente ocorre é um entendimento a nível mental e uma repetição mecânica do modo de estar no mundo de acordo com o primeiro modelo.

O segundo modelo de concepção de como percebemos e nos posicionamos no mundo coloca o sujeito como ponto central. A física quântica chega a afirmar que a realidade só colapsa quando há a existência do sujeito. É somente a presença do observador que atesta uma realidade. A máxima central repousa no questionamento: o que é real sem testemunhas? Ou seja, em princípio, algo só é real, quando há um observador para afirmar que é real e ao olhar para a realidade, esta é influenciada pelo olhar do observador. A mesma lógica é expressa por Maturana ao afirmar que Tudo o que é dito, é dito por um observador (idem, p. 31).

Mas se o objeto só existe se o sujeito existe, não há 'cadeira' independente do observador? E no caso de um cego: ele não vê a cadeira, e mesmo assim esbarra nela. Ora, a cadeira só passa a ser algo existente no momento em que ele a toca. Antes de ser percebida é algo inexistente, no mundo perceptivo do cego.

No caso da cadeira, da lousa, das pessoas, elas não dizem de si, mas o olhar do observador vai determinar o que são e como são. Em se tratando da cadeira, somos nós, os próprios sujeitos, que construímos cadeiras. E, só reconhecemos a cadeira como cadeira, por nossa convivência social que constrói cadeiras (passado).

E sobre a cor? É nossa capacidade de ver a cor vermelha que nos leva a perceber a existência desta cor. Isto porque, em nossa organização biológica, somos dotados de um determinado espectro prismático que nos permite perceber uma gama de cores, quando sofremos determinadas perturbações do meio. Mas como é que, praticamente, todos vemos a mesma cor? Porque temos uma estrutura orgânica similar que nos permite compartilhar um mundo consensual. Mas, lembrando do daltônico, já que tem uma constituição física diferente, não vê o vermelho e sim a cor verde.

Os cachorros e os felinos têm outro espectro de cores, outra formação na retina e, portanto, não vêem o mesmo mundo que nós vemos. Na verdade, não vemos o mundo 'lá fora', configuramos um mundo de acordo com nossas estruturas sociais, orgânicas e psíquicas. O mundo 'objetivo' é diferente para cada ser vivo que tem uma constituição biológica diferente. Cada espécie configura seu próprio espaço, tempo, cores. etc.

Id en line Revista de Psicologia. Ano 7, No. 21, Novembroo/2013 - ISSN 1981-1179

Edição eletrônica em http://idonline.emnuvens.com.br/id 
Se ocorrerem modificações em nossa constituição, ocorrem modificações na maneira como percebemos o mundo. Um exemplo bastante claro deste processo é o caso de se formos acidentados, dependendo dos danos que sofremos, iremos mudar completamente nossa maneira de perceber e estar no mundo.

Também no caso de uma pessoa com enfermidade ocular, sua visão é distorcida em relação ao meio. Se ela passa a utilizar um aparelho corretivo - óculos - ela passa a perceber o meio de uma maneira completamente diferente. Se não usa óculos, vê o mundo de uma forma, se está com óculos o mundo percebido é outro. O espaço visual também se apresenta diferente, se ela usa lentes de contato, ou se usa óculos escuros. Toda a percepção muda, conforme a lente é usada para ver 'a realidade'. A lente utilizada para ver vai indicar o que é visto.

Ao questionar sobre a relação entre sujeito e objeto, recordo-me de uma pergunta feita neste sentido. Se jogar um objeto de um prédio de 20 andares, o que vai acontecer depende da interação do objeto com a superfície na qual vai cair? Resposta: O que vai acontecer com o objeto jogado, depende da estrutura do objeto e o que vai acontecer com a superfície na qual foi jogado depende de como é constituída esta superfície. Se for jogada uma borracha, o que acontecerá com o choque no chão dependerá da constituição da borracha; se for jogado um copo de vidro o que acontecerá com o copo de vidro depende de sua estrutura, do material de que é feito. O mesmo vale para a superfície.

Obviamente, no encontro entre duas pessoas seres, nós nos modulamos reciprocamente. A maneira como $\mathrm{X}$ age vai provocar uma resposta em Y. Existe uma interação e agir de uma ou outra maneira pode fazer grandes diferenças no tipo de relacionamento. Mas sempre a resposta de $\mathrm{X}$, será determinada pela estrutura psíquica e contexto de $\mathrm{X}$, o mesmo acontecerá com a resposta de $\mathrm{Y}$.

\section{Referência:}

MATURANA, H. e VARELA, F. A árvore do conhecimento. As bases biológicas da compreensão humana. São Paulo, Palas Athena, 2001.

\section{Como citar este artigo (Formato ISO):}

PIERRE, Cláudia Maria Moura.. Ensaio sobre a Percepção. Id on Line Revista de Psicologia, Novembro de 2013, vol.1, n.21, p. 10-14. ISSN 1981-1189.

Id en lime Revista de Psicologia. Ano 7, No. 21, Novembroo/2013 - ISSN 1981-1179. Edição eletrônica em http://idonline.emnuvens.com.br/id 